\title{
Hip and groin time-loss injuries decreased slightly but injury burden remained constant in men's professional football: the 15-year prospective UEFA Elite Club Injury Study
}

\author{
Jonas Werner, ${ }^{1,2}$ Martin Hägglund, ${ }^{\circledR 2,3}$ Jan Ekstrand, ${ }^{2,4}$ Markus Waldén ${ }^{2,4,5}$
}

'Department of Orthopaedics, Vrinnevisjukhuset, Norrköping, Sweden

${ }^{2}$ Football Research Group, Linköping, Sweden

${ }^{3}$ Division of Physiotherapy, Department of Medical and Health Sciences, Linköping University, Linköping, Sweden ${ }^{4}$ Division of Community Medicine, Department of Medical and Health Sciences, Linköping University, Linköping, Sweden

${ }^{5}$ Department of Orthopaedics, Hässleholm-Kristianstad-Ystad Hospitals, Hässleholm, Sweden

\section{Correspondence to}

Dr Jonas Werner, Department of Orthopaedics, Vrinnevisjukhuset, Norrköping SE-603 79, Sweden; jonas.werner@

regionostergotland.se

Accepted 30 March 2018

Published Online First

24 April 2018
Check for updates

To cite: Werner J, Hägglund $\mathrm{M}$, Ekstrand J, et al. Br I Sports Med 2019:53:539-546.

\section{ABSTRACT}

Background Hip and groin injuries are common in men's professional football, but the time-trend of these injuries is not known.

Aim To investigate hip and groin injury rates, especially time-trends, in men's professional football over 15 consecutive seasons.

Study design Prospective cohort study.

Setting Men's professional football.

Methods 47 European teams were followed prospectively for a varying number of seasons between 2001/2002 and 2015/2016, totalling 268 team seasons. Time-loss injuries and individual player exposure during training and matches were recorded. Injury rate was defined as the number of injuries/1000 hours and injury burden as the number of lay-off days/1000 hours. Time-trends for total hip and groin injuries and adductor-related injury rates were analysed using Poisson regression, and injury burden was analysed using a negative binomial regression model.

Results Hip and groin injuries contributed 1812 out of 12736 injuries (14\%), with adductor-related injury as the most common of hip and groin injuries $(n=1139,63 \%)$. The rates of hip and groin injury and adductor-related injury were $1.0 / 1000$ hours and $0.6 / 1000$ hours, and these rates decreased significantly with on average $2 \%(\operatorname{Exp}(b)=0.98$, $95 \% \mathrm{Cl} 0.97$ to $0.99, \mathrm{P}=0.003)$ and $3 \%(\operatorname{Exp}(\mathrm{b})=0.97$, $95 \% \mathrm{Cl} 0.95$ to $0.99, \mathrm{P}<0.001)$ per season (year on year), respectively. The seasonal trend of hip and groin injury burden did not improve $(\operatorname{Exp}(b)=0.99,95 \% \mathrm{Cl} 0.97$ to 1.01, $\mathrm{P}=0.40$ ).

Conclusions Hip and groin injuries constitute a considerable part of all time-loss injuries in men's professional football. Although there was a promising slight decreasing trend in the rates of hip and groin injury (as a category) and adductor-related injury (as a specific diagnosis), the injury burden remained at a consistent level over the study period.

\section{INTRODUCTION}

Professional football has high injury rates, with an average player sustaining two time-loss injuries per season. ${ }^{1}$ Hip and groin injuries (HGI) are among the most common football injuries and account for $12 \%-16 \%$ of all recorded time-loss injuries per season in men's professional football. ${ }^{2}$ Similarly, a recent study of male football players in Qatar found that HGI accounted for $18 \%$ of all time-loss injuries. $^{3}$ This high rate is probably due to the repetitive involvement of sprinting, kicking and change of direction. $^{4-6}$
In a systematic review on different football codes, a stable trend for total HGI rate was found with an increasing trend of intra-articular hip joint conditions over the past decade. ${ }^{7}$ This trend could reflect an actual increase of hip injuries or reflect diagnostic changes, considering the increasing rate of arthroscopic hip surgery seen both in the USA and Europe over the last $10-15$ years. ${ }^{8} 9$ There is thus a need for studies on HGI in sports with longer follow-up periods and using appropriate time-trend analyses. ${ }^{10}$

The aim of this study was to investigate HGI rates, especially time-trends, in men's professional football over 15 consecutive seasons. Our hypothesis was that the overall HGI rate would be stable over multiple seasons.

\section{MATERIALS AND METHODS}

This is a substudy of the UEFA Elite Club Injury Study, ${ }^{1}$ including some seasonal data on HGI published previously. ${ }^{2}$ In total, 47 men's professional teams from 16 European countries were followed over a varying number of seasons (on average 5.7 seasons per team, range 1-15) from $2001 / 2002$ to $2015 / 2016$. The study has involved 3055 individual players (7756 player seasons) and 268 team seasons. Nine teams participated the inaugural year of the study, but the study has expanded and in the 2015/2016 season 28 clubs were included. The study design adhered to the consensus statement on injury definitions and data collection procedures in football, ${ }^{11}$ and the overall methodology has been reported in detail elsewhere. ${ }^{12}$ The recent Doha agreement on terminology of groin pain, ${ }^{13}$ a clinically based taxonomy to improve standards in research of HGI, was used to classify all the HGIs. During this procedure, all HGIs were reclassified by the primary author from the Orchard Sports Injury Classification System (OSICS) used in the database. ${ }^{14}$ For the purpose of this substudy, injuries were categorised according to the Doha agreement on terminology of groin pain into adductor-related, iliopsoas-related, pubic-related, inguinal-related, hip joint-related and other causes of groin pain. ${ }^{13}$ Compared with the classification used in our previous study, rectus abdominis tendinopathy and symphysitis/pelvic stress fracture were grouped into the pubic-related category. Consequently, the category 'other causes of groin pain' includes diagnoses such as groin enthesiopathy and groin tendinopathy as well as nerve entrapment. 


\begin{tabular}{|c|c|}
\hline Training session & $\begin{array}{l}\text { Team training that involved physical activity under the } \\
\text { supervision of the coaching staff. }\end{array}$ \\
\hline Match & Competitive or friendly match against another team. \\
\hline Injury & $\begin{array}{l}\text { Any physical complaint sustained by a player that resulted } \\
\text { from a football match or football training and led to the } \\
\text { player being unable to take full part in future football } \\
\text { training or match play. }\end{array}$ \\
\hline Hip and groin injury & $\begin{array}{l}\text { Injury located to the hip joint or surrounding soft tissues or } \\
\text { at the junction between the anteromedial part of the thigh, } \\
\text { including the proximal part of the adductor muscle bellies, } \\
\text { and the lower abdomen. }\end{array}$ \\
\hline Reinjury & $\begin{array}{l}\text { Injury of the same type and location as a previous injury } \\
\text { that occurred within } 2 \text { months of a player's return to full } \\
\text { participation. }\end{array}$ \\
\hline Slight/minimal injury & Injury causing $0-3$ days lay-off. \\
\hline Mild injury & Injury causing 4-7 days lay-off. \\
\hline Moderate injury & Injury causing 8-28 lay-off. \\
\hline Severe injury & Injury causing $>28$ days lay-off. \\
\hline Acute injury & Injury with sudden onset and known event. \\
\hline Overuse injury & Injury with insidious onset and no identifiable event. \\
\hline Injury rate & $\begin{array}{l}\text { Number of injuries per } 1000 \text { player hours }((\Sigma \text { injuries } / \Sigma \\
\text { exposure hours }) \times 1000) \text {. }\end{array}$ \\
\hline Injury burden & $\begin{array}{l}\text { Number of lay-off days per } 1000 \text { player hours ( }(\Sigma \text { lay-off } \\
\text { days } / \Sigma \text { exposure hours }) \times 1000)\end{array}$ \\
\hline
\end{tabular}

\section{Inclusion criteria and definitions}

All players in the first team squad were invited each season to participate. Players who were transferred or finished their contracts due to other reasons before the end of a season were included for as long as they participated in first team activities. Injury was defined according to time-loss, and players were considered injured until the club medical staff allowed full participation in training and availability for match selection. ${ }^{11}{ }^{12}$ In this study, a recordable HGI was defined as an acute or overuse injury located to the hip (the hip joint and surrounding soft tissues) or groin (the junction between the anteromedial part of the thigh and the lower abdomen) regions. ${ }^{211}$ All operational definitions used in this substudy are seen in table 1 . Reinjuries were defined according to the concept of early recurrences. ${ }^{11}$

\section{Data collection}

Baseline player data collection and consent was collected once yearly at the time of inclusion. A member of each club's medical team or technical staff registered individual exposure in minutes during club and national team training sessions and matches. A club medical officer (physician or physiotherapist) recorded all injuries immediately after the incident. Injury cards and attendance records were sent to the study group monthly, starting with July each season during the preseason preparation period and ending in May the following year. If a player was injured at the end of the season, the study controllers collected additional information on when the player was considered fully fit to return to play in the off-season. Prompt feedback was given to the participating teams by our study controllers in order to correct missing or unclear data. Seasonal data were aggregated on a team level.

\section{Statistical analyses}

Injury rate (IR) was calculated as the number of injuries per 1000 hours with corresponding 95\% CI. Injury burden was calculated as the number of lay-off days per 1000 hours with corresponding 95\% CI. Lay-off days was presented as mean $\pm \mathrm{SD}$.
Poisson regression was used to analyse seasonal trend in total HGI, and subgroups adductor-related injury, acute and overuse injury, with number of injuries as dependent variable, season as independent variable and exposure entered as an offset in the model. A negative binomial regression model was used for injury burden, due to better model fit. ${ }^{15}$ All models were adjusted for overdispersion according to Pearson's correlation. A 2-year moving average (MA) approach, by summarising two consecutive seasons and averaging their values, was also used in order to smooth out large seasonal variations and presented as seasonal average percent change. ${ }^{16}$ As a sensitivity analysis, the aggregated IR for the 610 HGIs in the 2001/2002 to 2007/2008 seasons, as reported previously, ${ }^{2}$ was also compared with the aggregated IR for the subsequent eight seasons 2008/2009 to $2015 / 2016$ seasons. A rate ratio (RR) with $95 \%$ CI was used for IR comparisons between the two seasonal blocks (2001/2002 to $2007 / 2008$ and $2008 / 2009$ to $2015 / 2016$ ) and between match and training. The significance level was set at $\mathrm{P}<0.05$.

\section{RESULTS}

In total, 12736 injuries were registered during 1816071 exposure hours (1 529387 training and 286684 match). HGI was diagnosed in 1812 cases (912 training and 900 match), constituting 14\% of all injuries (table 2). The overall HGI rate was $1.0 / 1000$ hours, the match injury rate being five times higher compared with training (IR 3.1 vs $0.6 / 1000$ hours; RR 5.3, $95 \%$ CI 4.8 to 5.8). In effect, a men's professional football club with approximately 25 players in the squad would suffer from about six HGI per season when averaging the whole study period. The HGI rate reduction was $12 \%$ in the $2008 / 2009$ to 2015/2016 seasons compared with the 2001/2002 to 2007/2008 seasons (IR 0.96 vs $1.08 / 1000$ hours; RR $0.88,95 \%$ CI 0.80 to 0.97 ) (see online supplementary appendix 1 for detailed data covering the $2001 / 2002$ to $2007 / 2008$ seasons). Acute cause for HGI was seen in 888 cases (49\%) and overuse in 910 cases $(51 \%)$, respectively (missing data in 14 cases).

\section{Time-trends and injury characteristics}

The seasonal trend for HGI rates was statistically significant, with an average annual decrease of $2 \%$ per season $(\operatorname{Exp}(b)=0.98$, $95 \%$ CI 0.97 to $0.99, \mathrm{P}=0.003$, figure 1 ), and where the 2 -year MA approach indicated an average annual IR decrease of $1.8 \%$. This was mainly due to a decrease in the match IR, with an average annual decrease of $2.7 \%(\operatorname{Exp}(b)=0.97,95 \% \mathrm{CI} 0.96$ to $0.99, \mathrm{P}=0.003$, MA 2.4\% decrease per season, figure 2), whereas the training IR was stable over the study period $(\operatorname{Exp}(b)=0.99$, $95 \% \mathrm{CI} 0.97$ to $1.01, \mathrm{P}=0.50$, MA $0.01 \%$ decrease per season, figure 3).

In effect, a men's professional football club, with a typical 25 -player squad, which suffered from seven HGIs per season on average in 2001/2002 could expect a decrease to fewer than six HGIs per season at the end of the study period. The seasonal trend of HGI burden as described by lay-off days did not change significantly $(\operatorname{Exp}(b)=0.99,95 \%$ CI 0.97 to 1.01 , $\mathrm{P}=0.40$, figure 4 ), although the 2-year MA approach indicated an average annual decrease of $1.9 \%$. Consequently, injury severity as measured by lay-off days slightly increased, not paralleling the decrease in HGI rate. Regarding injury onset, a statistically significant $3 \%$ decrease per season was seen for acute HGIs $(\operatorname{Exp}(b)=0.97,95 \%$ CI 0.96 to $0.99, \mathrm{P}<0.001$, MA $2.3 \%$ decrease per season), while overuse HGI injury rates were stable with no statistically significant trend $(\operatorname{Exp}(b)=0.99,95 \% C I$ 


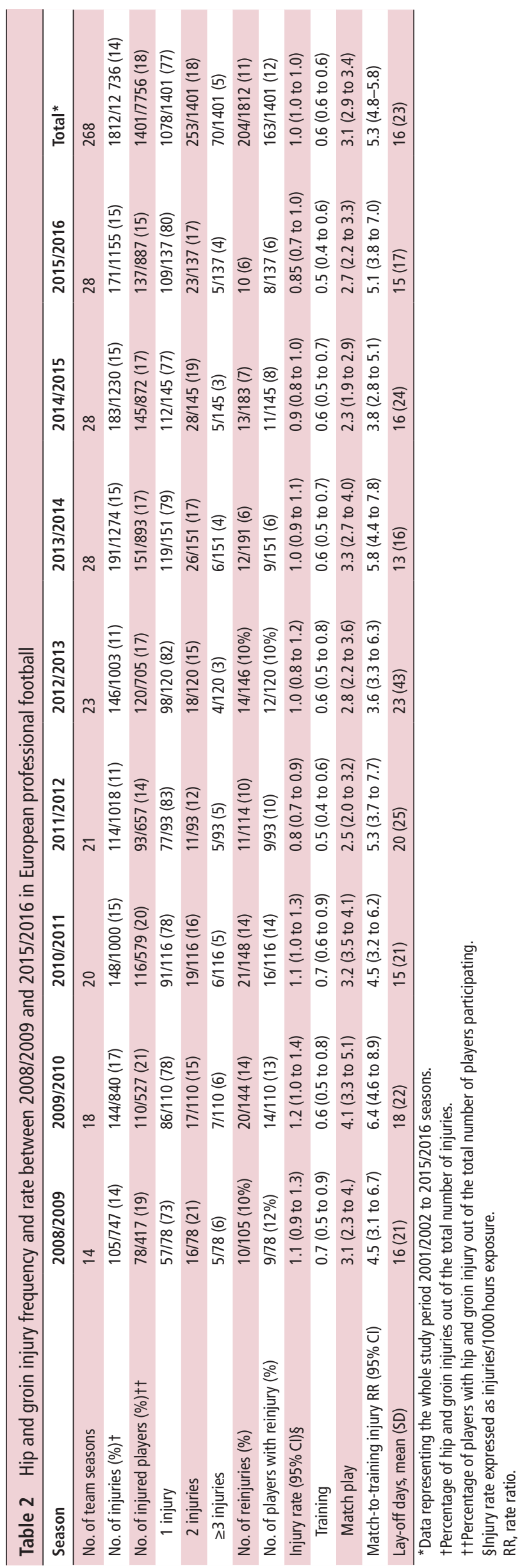

0.98 to $1.01, \mathrm{P}=0.43$, MA $1.8 \%$ increase per season) (see online supplementary appendix figure 2 and 3 ).

The most common HGI was adductor-related injury, totalling 1139 cases (63\% of all HGIs), thus making adductor-related injury twice as common as all other HGIs. The adductor-related IR was $0.6 / 1000$ hours (table 3 ), the match injury rate being six times higher compared with training (IR 2.2 vs $0.3 / 1000$ hours; RR 6.3, 95\% CI 5.7 to 7.1). Adductor-related injury also showed a statistically significant seasonal trend with an average annual decrease of $3 \%(\operatorname{Exp}(b)=0.97,95 \%$ CI 0.95 to $0.99, \mathrm{P}<0.001$, figure 5), and where the 2-year MA approach indicated an average annual IR decrease of $2.7 \%$. Adductor-related injury had the highest injury burden of all HGIs (table 3 ).

The second most common HGI was iliopsoas-related injury (8\% of all HGIs), whereas pubic-related, inguinal-related and hip-related injuries each constituted approximately 3\%-4\% of all HGIs (table 3). Hip-related injury was noted in 73 cases and the highest seasonal frequency $(n=13)$ was registered already in the inaugural 2001/02 season; hereafter, the number of cases registered each season was lower and rather stable in spite of an increasing number of participating teams and players in the study over the years. The most common diagnosis in this clinical entity was hip joint synovitis $(n=36)$, constituting the main diagnosis for half of all hip-related injuries, and another 11 cases were classified as hip cartilage lesions. Femoroacetabular impingement (FAI) was registered as the main diagnosis in only 10 cases ( 2 during the 2001/2002 to 2007/2008 seasons and 8 during the $2008 / 2009$ to $2015 / 2016$ seasons, respectively). Seasonal time-trend analyses were not computed for the iliopsoas-related, hip-related, pubic-related and inguinal-related injury groups due to the limited number of injuries.

\section{Reinjuries and multiple HGIs in the same season}

In total, $11 \%$ of all HGIs were reinjuries; $11 \%$ in the adductor-related injury group, whereas in the pubic-related and hip-related injury groups more than one out of four injuries were reinjuries (table 3). Of the 1401 players who sustained an HGI, $1078(77 \%)$ had only one injury during the season, $253(18 \%)$ had two injuries and $70(5 \%)$ suffered three or more injuries in the same season. On an individual level, 24\% (208/879) and $20 \%(25 / 126)$ of players sustaining an adductor-related and iliopsoas-related injury, respectively, will incur one or more additional HGI in the same season.

\section{DISCUSSION}

The principal finding of this study was that HGIs among male professional football players appear to have a slight decreasing trend over the 15-year observation period. This trend was mainly due to a decrease in adductor-related injuries, and these are positive findings even though the clinical importance in the short-term is limited. However, there was no decreasing trend seen for injury burden, suggesting that the slight reduction in number of HGIs was countered by a slight increase in severity of injury as measured by days lost to training and matches.

\section{Hip and groin injury epidemiology}

In a systematic review of prospective studies on groin injuries in senior football, every eighth time-loss injury affected the groin. ${ }^{10}$ In the current study, HGIs made up 11\%-17\% of all injuries, thus extending the knowledge of the existing literature. ${ }^{217-19} \mathrm{~A}$ certain amount of additional unrecorded complaints could be expected, since previous studies have shown that the prevalence of hip and groin pain during a season can be up to $70 \% .^{20-22}$ 
Hip and groin injury rate

-----.95\% Cl lower

----.95\% Cl upper

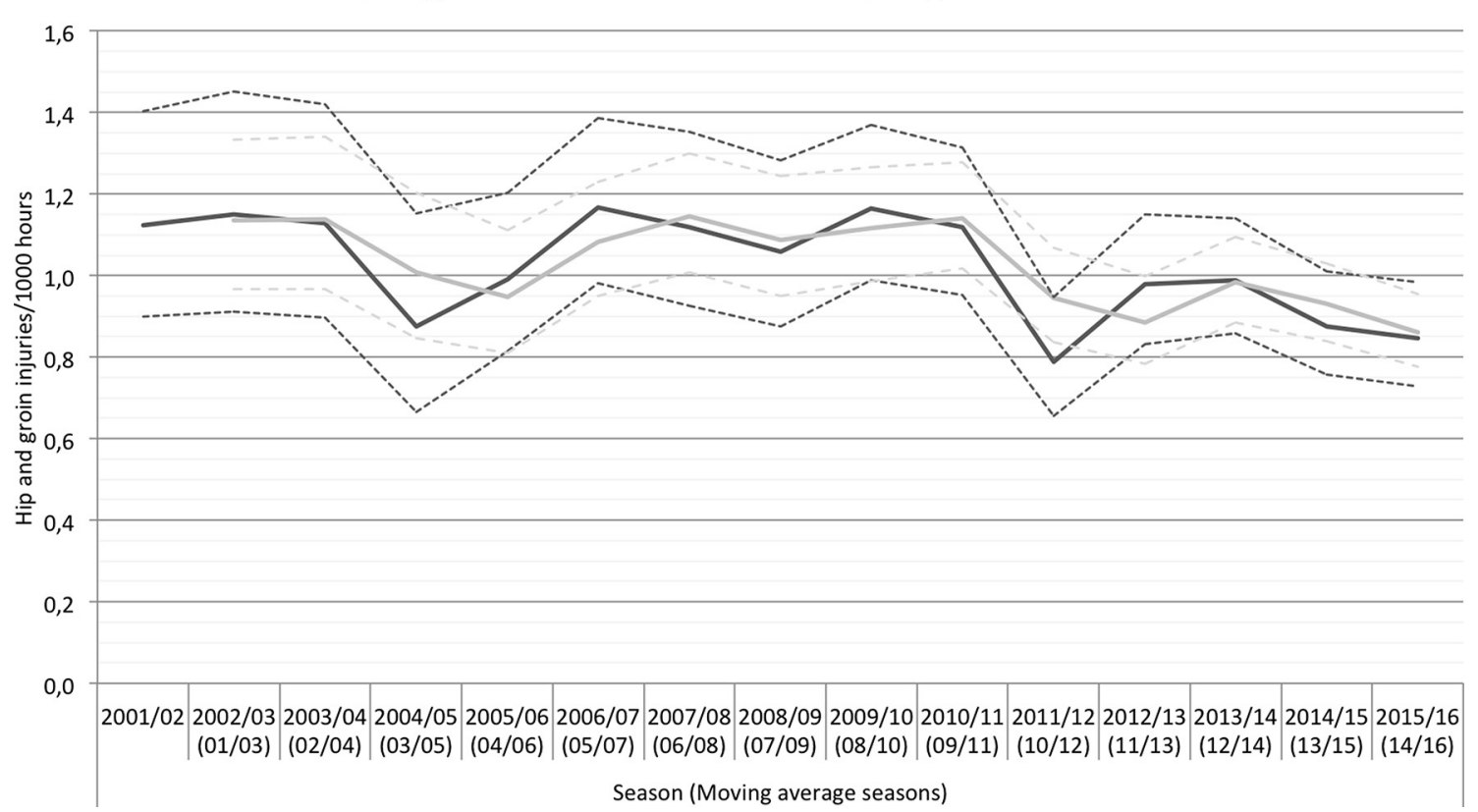

Moving average injury rate

95\% Cl lower

$95 \% \mathrm{Cl}$ upper

Figure 1 Hip and groin injury rates per season in European professional football. The light grey line shows the 2-year moving average injury rate calculated by summarising two consecutive seasons and averaging their values.

This is probably due to the fact that the pain often is insidious in onset and footballers play through a certain degree of discomfort. The use of a time-loss injury definition, as in the current study, therefore underestimates the overall HGI problem in football. On the other hand, time-loss injuries capture injuries with a clear impact for the teams since players are unavailable to train and play matches.
In the current study, we report an even distribution of acute and overuse injuries, even though there was a slight decreasing trend of acute injuries, which is in contrast to previous studies on both subelite male football as well as professional football in Qatar reporting about $40 \%$ of the HGIs to be of acute onset. ${ }^{36}$

In the present study, seasonal time-trend analyses showed a significant decrease of HGI of approximately $2 \%$ per season,

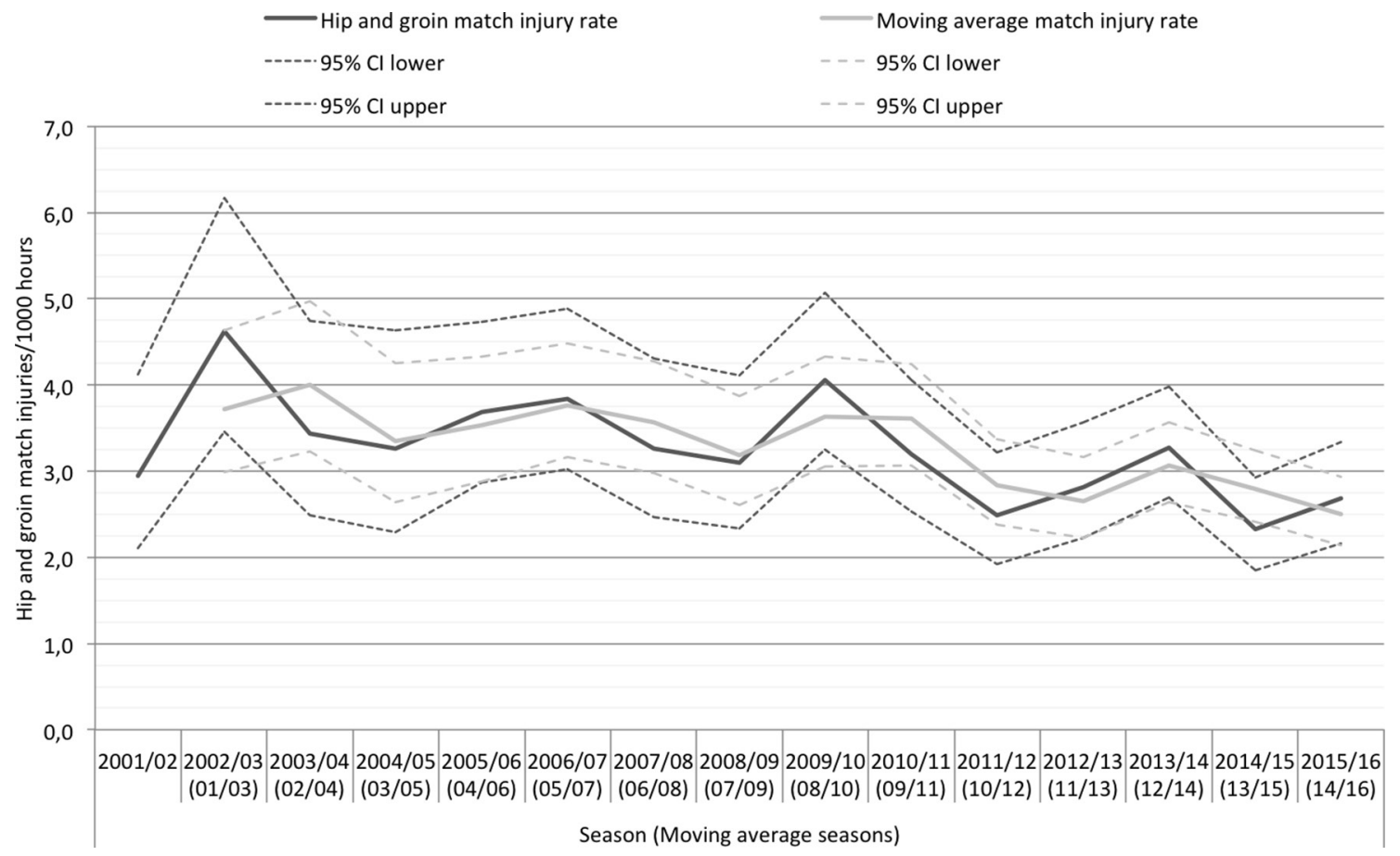

Figure 2 Hip and groin match injury rates per season in European professional football. The light grey line shows the 2-year moving average injury rate calculated by summarising two consecutive seasons and averaging their values. 


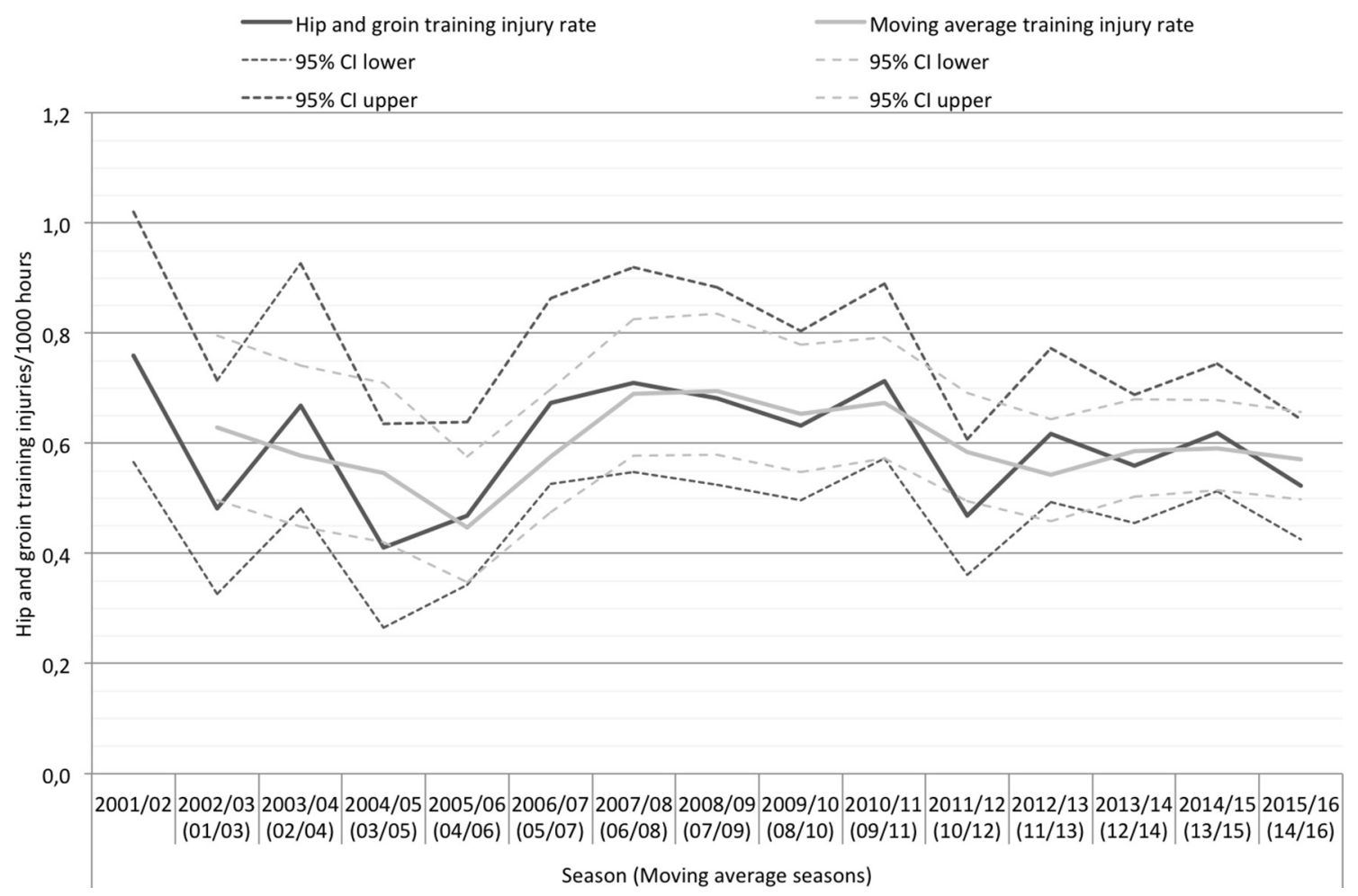

Figure 3 Hip and groin training injury rates per season in European professional football. The light grey line shows the 2-year moving average injury rate calculated by summarising two consecutive seasons and averaging their values.

which is in contrast to previous studies on different football codes. $^{7}$ In our previous study, the HGI rate was stable over seven consecutive seasons as assessed by visual inspection without any formal time-trend analysis being carried out at that time. ${ }^{2}$ In the current study involving another eight seasons, a $12 \%$ rate reduction was identified between the first and second study periods
(2001/2002 to $2007 / 2008$ and $2008 / 2009$ to $2015 / 2016$ ). A change of trend was noted mainly from the 2011/2012 season and onwards where the main contributing factor was a decrease of the HGI rate during match play.

Increased caution by the players and medical staffs on deciding whether a player with minor hip and groin symptoms

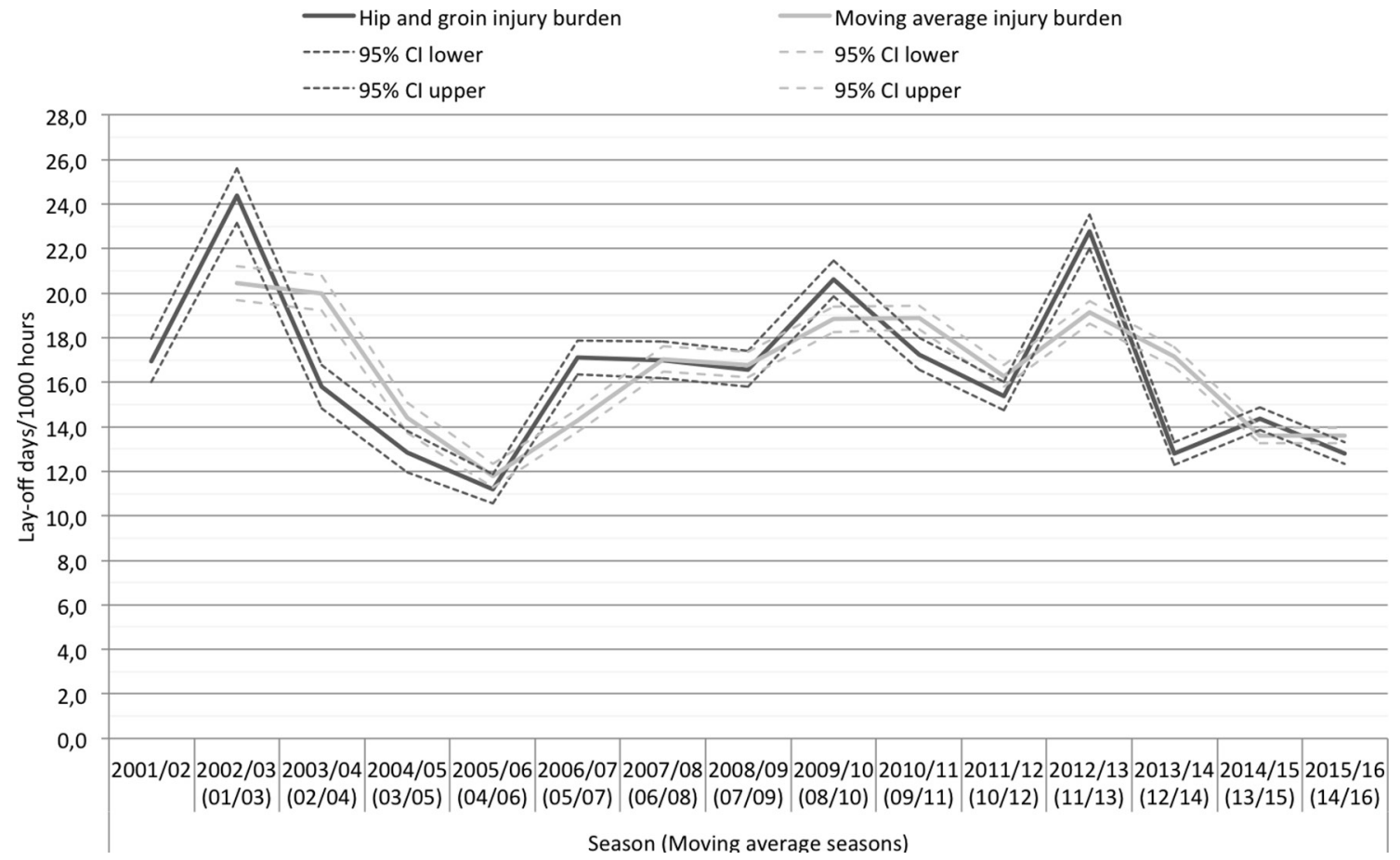

Figure 4 Hip and groin injury burden per season in European professional football. The light grey line shows the 2-year moving average injury rate calculated by summarising two consecutive seasons and averaging their values. 


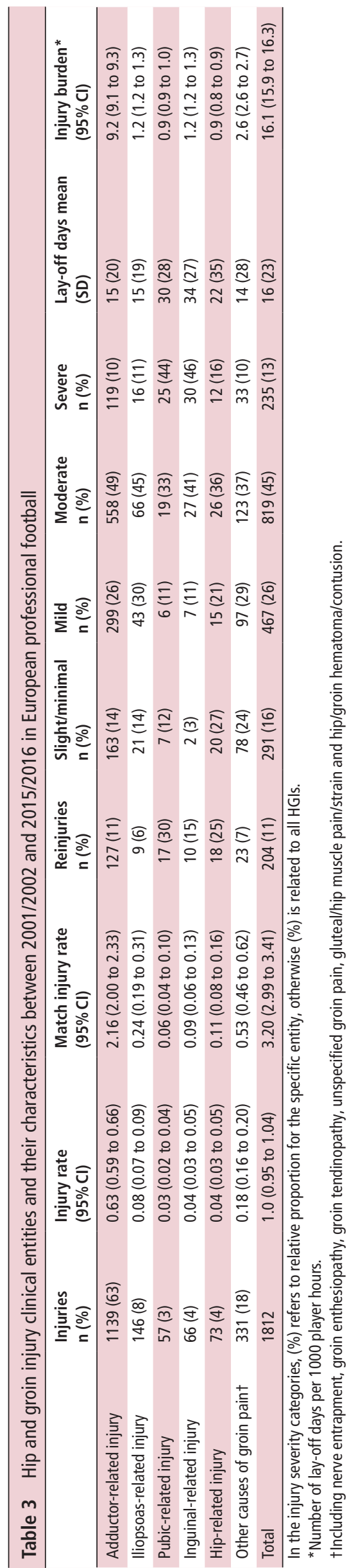

is eligible for match play, and a wider use and implementation of preventive training might contribute to this. However, injury burden as described by lay-off days did not show a significant decreasing trend, indicating that even though the HGI rate is decreasing, the number of lay-off days for these injuries remains high. From a team perspective, this is an important finding, since injury burden better describes the effects of an injury type for a club than injury rate alone. Even though injury burden may also underestimate the consequences of injuries not leading to time-loss, further analysis of this aspect of injury epidemiology is warranted. ${ }^{23} 24$

\section{Injury characteristics}

Adductor-related injury was the most frequently reported entity, making up just about two-thirds of all HGIs. This study thereby adds further evidence that adductor-related injury is the most common HGI in football. ${ }^{236}$ Interestingly, we found a significant decrease in the rate of adductor-related injury, and this has to our knowledge not been shown in football or any other sport previously. It has been suggested that eccentric forces stressing the musculotendinous complex when kicking and changing directions contributes to adductor-related injury. ${ }^{22}$ Moreover, relative weakness of hip adduction is a risk factor for groin injury. ${ }^{25}$

In previous studies on treatment of long-standing adductor-related groin pain, an active strengthening programme showed effect both in the short-term (OR of 12.7 in favour of the active treatment group on return to sports without groin pain) and in the long-term (significantly better treatment outcomes in the subgroup of football players). ${ }^{26}$ Accordingly, groin injury preventive measures have focused on active strength and coordination exercises, with emphasis on the adductor and abdominal muscles. ${ }^{25}$ We hope that the use of these prevention strategies and an increased overall knowledge on HGI in the medical staffs of professional football clubs accounts for the decreasing trend of these injuries.

Interestingly, the second most common entity of HGI constitutes other causes of groin pain. This highlights the diagnostic challenges of HGI and points towards the historical problem with different taxonomy on HGI without consensus. ${ }^{13}$ On a positive note, this entity had the shortest lay-off time and lowest reinjury rate of all HGI indicating somewhat less severe injuries in this unspecified group of injuries.

\section{Recurrent injury: a clinical concern}

Previous HGI has been identified as the most prominent risk factor for HGI and in this respect reinjuries are known to cause longer lay-off times. ${ }^{2} 62829$ For example, Árnason et al reported a sevenfold increased risk of groin injury in footballers with previous groin injury. ${ }^{30}$ In our previous study, reinjuries accounted for $15 \%$ of all $\mathrm{HGIs}^{2}$ In the current study, however, the average reinjury frequency was $11 \%$ when analysing the whole study period, indicating a slight decrease over the study period even though this was not specifically analysed. It could be speculated that one cause for this could be that more cautious and specific rehabilitation programmes (eg, focusing on movement patterns, abdominal and adductor strength and complete physical conditioning) have been implemented for adductor-related and iliopsoas-related injuries where the reinjury frequencies were lower than for other entities. ${ }^{27}$ However, the scientific evidence for treatment strategies of groin pain is generally low, with moderate evidence for active exercise therapy or multimodal treatment 


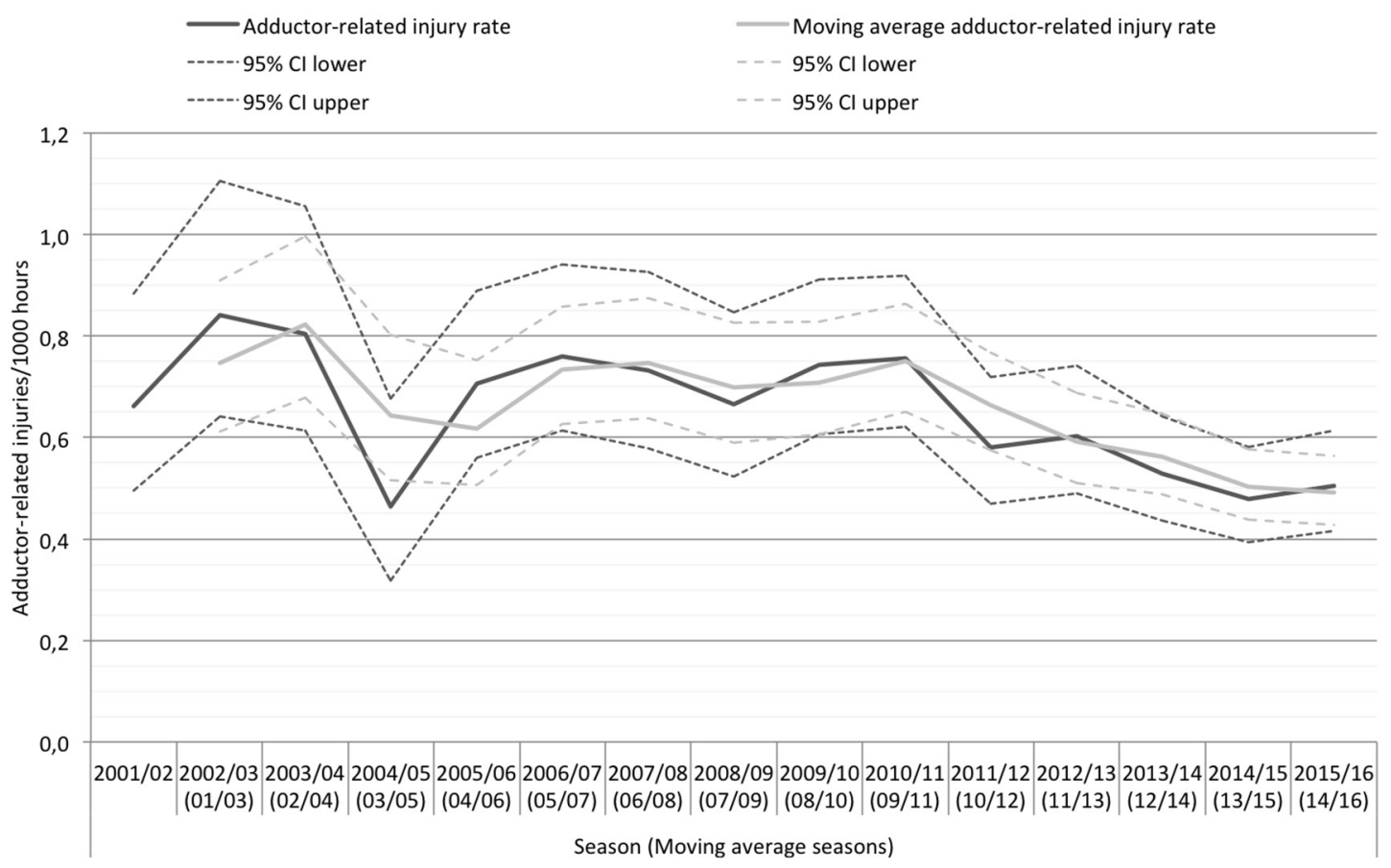

Figure 5 Adductor-related injury rates per season in European professional football. The light grey line shows the 2-year moving average injury rate calculated by summarising two consecutive seasons and averaging their values.

in long-standing adductor-related groin pain. ${ }^{31}$ Another plausible explanation could be that more attention is paid to individual load, mainly the acute-to-chronic workload ratio, since this has been shown to be an important predictor of injury. ${ }^{32}$ However, we also found that $23 \%$ of players with a HGI would suffer from at least one more HGI during the same season. Caution concerning symptoms of HGI is therefore recommended throughout the whole season for players who have had a time-loss HGI and continuous secondary preventive measures should be considered.

\section{Hip-related injuries}

The increase in hip-related injuries reported in other football codes during recent years ${ }^{7}$ could not be reproduced in our study in spite of not being able to carry out the formal timetrend analyses due to few cases per season which is a limitation of the method. The physical nature including full speed tackling, forceful blocks as well as high energy falls in for example, Australian Rules football and American football could explain the difference between football and these sports. The most common hip-related diagnosis in our study was hip joint synovitis, which merely may reflect just temporary overload and tend to resolve rather quickly. This notion is supported by the fact that most of the hip synovitis injuries were classified as mild or moderate and the mean lay-off was clearly lower than the mean lay-off for the whole HGI group (6 vs 16 days).

We found only 10 cases with FAI as the main diagnosis on the injury card, which is $<1 \%$ of all HGIs. It is, however, still possible that FAI was a contributing factor in some of the other hip-related injuries such as joint synovitis or joint cartilage lesion. Nevertheless, considering that previous studies have indicated that radiographic cam-lesions are more prevalent in footballers, ${ }^{33}$ our study does not support the idea that FAI is an increasing cause for injury in professional football. Cam and pincer changes are to be considered as morphological variants of the femur and acetabulum, but this does not automatically imply pathology in the form of the FAI syndrome. ${ }^{34}$ Radiological signs of FAI is also frequently observed in patients with for example, long-standing adductor-related pain, and there is a weak correlation between hip morphology and symptoms. ${ }^{35}$

\section{Strengths and limitations}

The principal strength of the current study is the prospective design over 15 consecutive seasons with a comprehensive dataset on a homogenous group of male professional footballers and terminology adherent to the recent Doha agreement on terminology of groin pain. ${ }^{13}$ To the best of our knowledge, this is one of the largest cohorts ever to be studied prospectively for HGI in professional sports. ${ }^{36-38}$

We note four additional limitations. First, there were no defined specific diagnostic criteria for different HGI to guide the medical staff. The diagnoses were solely based on the best clinical practice in each club and from our previous study we know that $40 \%$ relied on clinical examination exclusively without additional imaging. ${ }^{2}$ It is also well-known that the number of differential diagnoses are considerable concerning HGI and the lack of common terminology for groin pain and injuries before the Doha consensus may have influenced the number of unspecific diagnosis. This could partly explain why such a substantial number of cases were diagnosed as 'groin enthesiopathy' and 'groin tendinopathy'. Some of these injuries could probably have been classified in the adductor-related or iliopsoas-related injury groups, had these entities been chosen directly by the club medical staffs. This reflects a problem with reclassifying to the somewhat broader Doha agreement on terminology entities retrospectively.

A second limitation is that HGIs often present with both primary and secondary, and even tertiary, symptoms, which is known to increase lay-off times. ${ }^{6}$ This study is, however, unable to identify players with two or more diagnostic entities of HGI occurring simultaneously, since only the main diagnosis is entered and systematically OSICS coded in the 
database. Third, no information on specific treatment details, nor preventive strategies, was collected, and it would have been interesting to relate different treatment plans to lay-off times and recurrence rates as well as the effect of preventive measures on HGI rate. Finally, the interpretation of additional HGI during the same season should be made bearing in mind that an injury sustained in the fall will have a higher reoccurring risk during the season than an injury sustained in the spring. If, on the other hand, an approach using a calendar year would be used, some players would be 'exposed' to the period in between seasons, where rest and rehabilitation is part of normal life for a professional football player.

\section{What are the findings?}

- Hip and groin injury (HGI) rates have decreased slightly over the past 15 years in men's professional football, including adductor-related injuries, which is the most common clinical entity.

- HGI burden remained unchanged - this metric takes both the rate and severity of injuries into consideration.

- Despite the recent surge in the number of hip arthroscopies being carried out worldwide, hip-related injuries continue to have a low time-loss injury rate in men's professional football.

\section{How might it impact on clinical practice in the future?}

- The slight decreasing trend in the rate of $\mathrm{HGl}$, as shown in the current study, is a promising finding and should motivate players, medical staffs and coaches to incorporate recent evidence when working with HGI treatment and prevention.

\section{Twitter Follow@jonwe747, @MHgglund, @janekstrand, @MarkusWalden, @} frgsweden.

Acknowledgements The authors would like to thank the participating clubs (coaching and technical staff, medical teams and players) for their participation in the study. Henrik Magnusson, MSc, is also acknowledged for statistical advice.

Contributors JW and MW were responsible for the conception and design of the study. JW and the statistical advisor conducted the analyses, which were planned and checked with MW, MH and JE. All authors contributed to the interpretation of findings and had full access to all data. JW wrote the first draft of the paper, which was critically revised by MW, MH and JE. The final manuscript has been approved by all authors. MW is the study guarantor.

Funding The Football Research Group has been established in Linköping, Sweden, in collaboration with Linköping University and through grants from the Union of European Football Associations and the Swedish National Centre for Research in Sports.

\section{Competing interests None declared.}

\section{Patient consent Obtained}

Ethics approval The study design was approved by the UEFA Medical Committee and the UEFA Football Development Division.

Provenance and peer review Not commissioned; externally peer reviewed.

(c) Article author(s) (or their employer(s) unless otherwise stated in the text of the article) 2019. All rights reserved. No commercial use is permitted unless otherwise expressly granted.

\section{REFERENCES}

1 Ekstrand J, Hägglund M, Kristenson K, et al. Fewer ligament injuries but no preventive effect on muscle injuries and severe injuries: an 11-year follow-up of the UEFA Champions League injury study. Br J Sports Med 2013;47:732-7.

2 Werner J, Hägglund $M$, Waldén $M$, et al. UEFA injury study: a prospective study of hip and groin injuries in professional football over seven consecutive seasons. Br J Sports Med 2009;43:1036-40.
3 Mosler AB, Weir A, Eirale C, et al. Epidemiology of time loss groin injuries in a men's professional football league: a 2-year prospective study of 17 clubs and 606 players. Br J Sports Med 2018;52: 292- 297.

4 Charnock BL, Lewis CL, Garrett WE, et al. Adductor longus mechanics during the maximal effort soccer kick. Sports Biomech 2009;8:223-34.

5 Brophy RH, Backus SI, Pansy BS, et al. Lower extremity muscle activation and alignment during the soccer instep and side-foot kicks. J Orthop Sports Phys Ther 2007:37:260-8.

6 Hölmich P, Thorborg K, Dehlendorff C, et al. Incidence and clinical presentation of groin injuries in sub-elite male soccer. Br J Sports Med 2014;48:1245-50.

7 Orchard JW. Men at higher risk of groin injuries in elite team sports: a systematic review. Br J Sports Med 2015;49:798-802.

8 Sing DC, Feeley BT, Tay B, et al. Age-related trends in hip arthroscopy: a large crosssectional analysis. Arthroscopy 2015;31:2307-13.

9 Palmer AJ, Malak TT, Broomfield J, et al. Past and projected temporal trends in arthroscopic hip surgery in England between 2002 and 2013. BMJ Open Sport Exerc Med 2016;2:e000082.

10 Waldén $M$, Hägglund $M$, Ekstrand J. The epidemiology of groin injury in senior football: a systematic review of prospective studies. Br J Sports Med 2015;49:792-7.

11 Fuller CW, Ekstrand J, Junge A, et al. Consensus statement on injury definitions and data collection procedures in studies of football (soccer) injuries. Br J Sports Med 2006:40:193-201.

12 Hägglund M, Waldén M, Bahr R, et al. Methods for epidemiological study of injuries to professional football players: developing the UEFA model. Br J Sports Med 2005;39:340-6.

13 Weir A, Brukner P, Delahunt E, et al. Doha agreement meeting on terminology and definitions in groin pain in athletes. Br J Sports Med 2015;49:768-74.

14 Rae K, Orchard J. The Orchard Sports Injury Classification System (OSICS) version 10. Clin J Sport Med 2007;17:201-4.

15 Agresti A. Generalized linear models. An introduction to categorical data analysis. Second Edn. Hoboken, New Jersey: John Wiley \& Sons, Inc, 2007:74-83.

16 Rosenberg D. Trend analysis and interpretation: key concepts and methods for maternal and child health professionals. Washington DC: Department of Health and Human Services, 1997

17 Hawkins RD, Hulse MA, Wilkinson C, et al. The association football medical research programme: an audit of injuries in professional football. Br J Sports Med 2001:35:43-7.

18 Hägglund $M$, Waldén $M$, Ekstrand J. Injury incidence and distribution in elite football-a prospective study of the Danish and the Swedish top divisions. Scand J Med SCi Sports 2005;15:21-8

19 Waldén M, Hägglund M, Ekstrand J. UEFA Champions League study: a prospective study of injuries in professional football during the 2001-2002 season. Br J Sports Med 2005;39:542-6.

20 Thorborg K, Serner A, Petersen J, et al. Hip adduction and abduction strength profiles in elite soccer players: implications for clinical evaluation of hip adductor muscle recovery after injury. Am J Sports Med 2011;39:121-6.

21 Hanna CM, Fulcher ML, Elley CR, et al. Normative values of hip strength in adult male association football players assessed by handheld dynamometry. I Sci Med Sport 2010:13:299-303.

22 Esteve E, Rathleff MS, Bagur-Calafat C, et al. Prevention of groin injuries in sports: a systematic review with meta-analysis of randomised controlled trials. $\mathrm{Br}$ J Sports Med 2015:49:785-91.

23 Bahr R, Clarsen B, Ekstrand J. Why we should focus on the burden of injuries and illnesses, not just their incidence. Br J Sports Med 2017:bjsports-2017-098160 (accessed 11 Oct 2017)

24 Hägglund $M$, Waldén $M$, Magnusson $H$, et al. Injuries affect team performance negatively in professional football: an 11-year follow-up of the UEFA Champions League injury study. Br J Sports Med 2013;47:738-42.

25 Thorborg K, Branci S, Nielsen MP, et al. Eccentric and isometric hip adduction strength in male soccer players with and without adductor-related groin pain: an assessorblinded comparison. Orthop J Sports Med 2014;2:22.

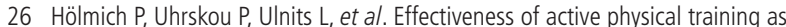
treatment for long-standing adductor-related groin pain in athletes: randomised trial. Lancet 1999:353:439-43.

27 Hölmich P, Nyvold P, Larsen K. Continued significant effect of physical training as treatment for overuse injury: 8- to 12-year outcome of a randomized clinical trial. Am J Sports Med 2011;39:2447-51.

28 Ryan J, DeBurca N, Mc Creesh K. Risk factors for groin/hip injuries in field-based sports: a systematic review. Br J Sports Med 2014;48:1089-96.

29 Maffey L, Emery C. What are the risk factors for groin strain injury in sport? A systematic review of the literature. Sports Med 2007;37:881-94.

30 Árnason A, Sigurdsson SB, Gudmundsson A, et al. Risk factors for injuries in football. Am J Sports Med 2004;32 (1 Suppl):5S-16S.

31 Serner $A$, van Eijck CH, Beumer BR, et al. Study quality on groin injury management remains low: a systematic review on treatment of groin pain in athletes. $\mathrm{Br} J$ Sports Med 2015;49:813. 
32 Gabbett TJ. The training-injury prevention paradox: should athletes be training smarter and harder? Br J Sports Med 2016:50:273-80.

33 Agricola R, Bessems JH, Ginai AZ, et al. The development of Cam-type deformity in adolescent and young male soccer players. Am J Sports Med 2012;40:1099-106.

34 Griffin DR, Dickenson EJ, O'Donnell J, et al. The Warwick agreement on femoroacetabular impingement syndrome (FAl syndrome): an international consensus statement. Br J Sports Med 2016;50:1169-76.

35 Weir A, de Vos RJ, Moen M, et al. Prevalence of radiological signs of femoroacetabular impingement in patients presenting with long-standing adductor-related groin pain. Br J Sports Med 2011:45:6-9.
36 Waldén $M$, Hägglund $M$, Ekstrand J. Time-trends and circumstances surrounding ankle injuries in men's professional football: an 11-year follow-up of the UEFA Champions League injury study. Br J Sports Med 2013;47:748-53.

37 Ekstrand J, Waldén M, Hägglund M. Hamstring injuries have increased by $4 \%$ annually in men's professional football, since 2001: a 13-year longitudinal analysis of the UEFA Elite Club injury study. Br J Sports Med 2016:50:731-7.

38 Waldén $M$, Hägglund $M$, Magnusson $H$, et al. $A C L$ injuries in men's professional football: a 15-year prospective study on time trends and return-to-play rates reveals only $65 \%$ of players still play at the top level 3 years after $A C L$ rupture. $B r$ J Sports Med 2016:50:744-50. 